\title{
Systematic monitoring of instrumentation health in high-density broadband seismic networks
}

\author{
Takeshi Kimura $^{1 *}$, Hiroshi Murakami ${ }^{2}$ and Takumi Matsumoto ${ }^{1}$
}

\begin{abstract}
Background: Broadband seismometer data are essential for the development of seismological studies such as those investigating earthquake sources and the Earth's structure. However, previous studies have revealed that the metadata describing these data can possibly be contaminated by instrumentation response errors that are often difficult to recognize from visual waveform checks. Herein, we report on the development of a systematic method of assessing seismometer conditions when recording ground motions at a period range of 50 to $200 \mathrm{~s}$ in observation networks whose station intervals are smaller than $200 \mathrm{~km}$.
\end{abstract}

Findings: The method is based on comparisons between teleseismic surface wave records at a target station and those at multiple surrounding reference stations, from which we calculate three index parameters and evaluate in situ instrumentation conditions, including amplitude and phase responses against input ground motions. In our experiments, we applied the proposed method to F-net broadband seismometers covering the Japanese Islands, where station intervals are approximately $100 \mathrm{~km}$. This allows us, through calculations of the index parameters, to evaluate instrumentation health at each station at least once every 60 days. Using our proposed method, we found that approximately $75 \%$ of the evaluated index parameters distributed well around the standard values, and for most examined broadband seismometers, response anomalies are not detected at the period range of 50 to $200 \mathrm{~s}$. However, instrumentation errors, such as gain decrease over the evaluated periods and gradual changes in amplitude and phase frequency responses (sometimes covering several years) were identified at a few stations. Additionally, overdamping errors at the STS-1 seismometers, which experience significant amplitude and phase frequency response variations around the 360-s corner, appear to have been common at several stations. In contrast, STS-2 seismometers appear to have functioned more reliably than STS-1 seismometers.

Conclusions: We developed a method to evaluate broadband seismometer instrument conditions by comparing teleseismic surface waves observed at a target station with those at multiple surrounding stations. It is believed that the systematic evaluation of instrumentation health using our method will enhance the operation of seismic networks, and allow researchers to eliminate contaminated data before conducting various data analyses.

Keywords: Seismic instrumentation health; Broadband seismometer; Amplitude frequency response; Phase frequency response; Teleseismic surface wave

\section{Findings}

\section{Background}

Modern broadband seismometer networks such as the Global Seismograph Network (GSN) have been developed for worldwide operation, while smaller networks such as the Berkeley Digital Seismic Network in northern and central California and the German Regional

\footnotetext{
* Correspondence: tkimura@bosai.go.jp

${ }^{1}$ National Research Institute for Earth Science and Disaster Prevention, 3-1, Tennodai, Tsukuba, Ibaraki 305-0006, Japan

Full list of author information is available at the end of the article
}

Seismic Network in Germany operate regionally. In Japan, the National Research Institute for Earth Science and Disaster Prevention (NIED) began the construction of a regional broadband seismograph network in 1995. At present, the network is referred to as F-net and consists of 73 stations positioned throughout the archipelago at intervals of approximately $100 \mathrm{~km}$ (Fukuyama et al. 1996; Okada et al. 2004; Matsumoto et al. 2009). Data acquired from F-net stations enable researchers to perform routine centroid moment tensor (CMT) analyses at regional distances (e.g., Fukuyama et al. 1998; 
Matsumura et al. 2006), image detailed velocity structures beneath and around the Japan Islands (e.g., Yoshizawa et al. 2010), and conduct studies of very low frequency earthquakes (e.g., Ito et al. 2007). All of the collected data is freely available on the NIED F-net website (http:// www.fnet.bosai.go.jp/top.php?LANG=en). As of 1 January 2014, NIED's F-net operated 18 STS-1, 54 STS-2, and 1 STS-2.5 broadband seismometers (Figure 1a).

Recent studies have reported a variety of instrument response deviations involving broadband seismometers, especially involving STS-1. For example, Yamada (2001) and Yuki and Ishihara (2002) revealed that STS-1 sensor tilting results in a damping constant fluctuation at the 360-s corner and that incomplete insulation between two feedback paths in the STS-1 seismometers due to humidity could make the damping constant higher. Additionally, Hutt and Ringler (2011) reported that the humid air inside STS-1 seismometer feedback electronics (FBE) produces not only the overdamped corner but also nonlinear responses against input amplitudes.

These broadband seismometer response error reports have resulted in the need for a method to identify possible instrumentation problems in situ (e.g., Davis et al. 2005; Ringler et al. 2012). However, because it is difficult to recognize subtle changes in seismometer conditions from visual checks of observed waveforms alone, additional methods have been developed to routinely assess such responses. Remote calibration through the calibration coil of an instrument is an effective method for identifying the seismometer frequency response precisely. However, the input of the calibration signal disturbs the ground motion records. As methods to evaluate the instrument condition in situ, Ekström et al. (2006) compared waveforms observed at GSN stations with synthetic waveform calculations based on estimated CMT solutions for $M_{W} \geq 6.5$ events and an assumed Earth's model, which indicated temporal changes in the amplitude frequency response at more than 15 stations. Ringler et al. (2010) observed variations of sensor conditions in a broad range of frequencies using power levels of background noises at GSN stations, and Davis and Berger (2007) assessed published GSN response information by comparing Earth's tide observations with synthetic tides at 1-day and half-day periods. Since the latter two approaches do not depend on the occurrence of seismic events, they can be used to evaluate instrument conditions at fixed intervals, which means they could help to identify sudden instrument condition changes.

In this study, we systematically evaluate the F-net broadband seismometer responses over a 50 to 200-s period range based on comparisons of seismic surface waves resulting from teleseismic earthquakes observed at a target station with those observed at multiple surrounding stations. In our proposed method, seismograms at stations around the target station are used as references to evaluate the seismometer condition at the target station. The target periods are included in the bandwidth used for F-net routine regional CMT analysis. The high station density of F-net enables us to correlate waveform data observed at multiple nearby stations in the period range. The availability of records from multiple surrounding stations provides multiple references

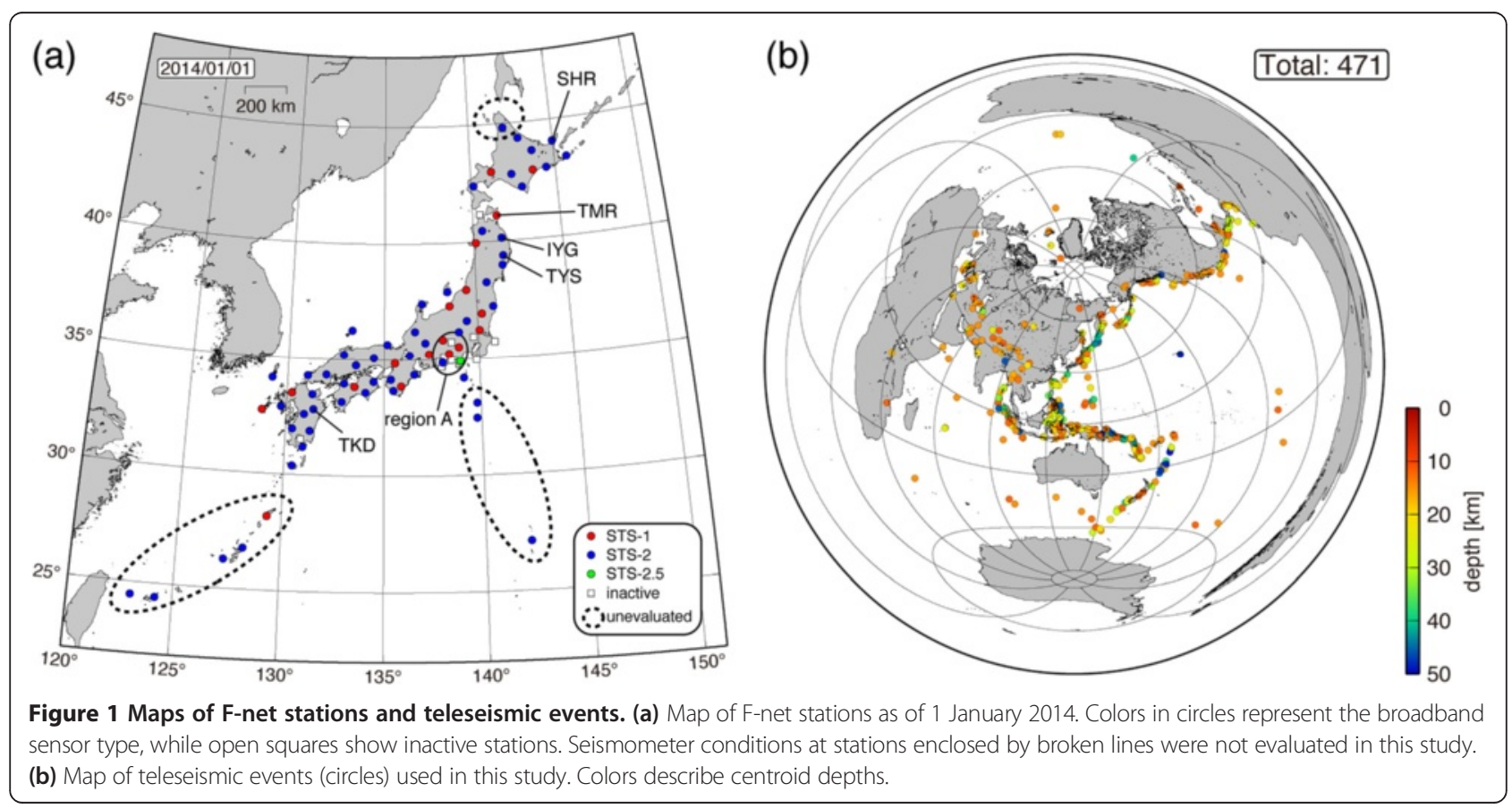


that allow us to evaluate the target instrumentation response free from possible instrument response errors at a few surrounding stations. This method is independent of the synthetic waveform calculations (Ekström et al. 2006), that is, CMT solution estimations, which are difficult to obtain from regional network data alone, and the uncertainty of Earth's model assumptions. Since background noise levels can be varied not only by deviations of instrument amplitude responses against input ground motions but also by deviations of the background noises themselves, including instrument noise, noise resulting from the installation of the instrument, and ambient seismic noise, it is impossible to infer the effects of observed noise level changes on ground motion record from noise monitoring (Ringler et al. 2010) alone. However, we can remove this ambiguity using seismic surface waves with significantly large amplitudes. In addition to verifying that most seismometers have responses that agree well with their reports, we could confirm that, at a small subset of stations, some types of instrument response errors have been issued for several years. Hereafter, among the revealed instrument errors, we will refer to the shift of amplitude frequency response curve (where the gain changes are constant over the evaluated periods) as the gain change and to the changes in the shape of amplitude and/or phase frequency response curves as the change in amplitude and/or phase frequency responses. We will also discuss the difference of the response errors between STS-1 and STS-2 seismometers.

\section{Data}

The locations of F-net stations and events used in this study are shown in Figure 1. From Global CMT catalog (Dziewonski et al. 1981; Ekström et al. 2012), we selected 471 teleseismic events in the 1995 to 2013 timeframe that occurred at depths shallower than $50 \mathrm{~km}$ and at magnitudes of 6.5 or larger in order to ensure that fundamental mode surface waves with large amplitudes were available. Events 2,000 to 14,000 km distant from each target station were analyzed in order to avoid overlapping with other phases at short distances and close to the anti-pole.

All the seismograms with the $1-\mathrm{Hz}$ sampling were deconvolved with the reported instrumentation responses and numerically integrated into displacements. The waveforms of the two horizontal components were rotated to produce radial and transverse components, which correspond approximately to Rayleigh and Love waves, respectively. We then applied bandpass filters at two period ranges (between 50 and $100 \mathrm{~s}$ and 100 and 200 s) against all waveforms. Time windows of the analyzed surface waves are automatically defined as those with durations of $400 \mathrm{~s}$ from $o+\left(\Delta_{\mathrm{tar}} / U\right)-100$ for periods of 50 to $100 \mathrm{~s}$, and of $800 \mathrm{~s}$ from $o+\left(\Delta_{\mathrm{tar}} / U\right)-200$ for periods of 100 to $200 \mathrm{~s}$, where $o, \Delta_{\operatorname{tar}}$ and $U$ are the centroid time of teleseismic event, distance between event and the target station, and assumed group speeds shown in Table 1 , respectively.

\section{Comparison with observed seismograms at a station}

Each extracted surface-wave part from the target station was matched with a seismogram taken from a surrounding reference station in order to ensure the maximum cross-correlation coefficient of the two seismograms. The maximum cross-correlation coefficient is searched within a lag time range of $\tau_{\text {syn }} \pm 10$ s. $\tau_{\text {syn }}$ is a synthetic lag time between two stations calculated with a planewave assumption as follows:

$$
\tau_{\text {syn }}=\frac{\Delta_{\mathrm{ref}}-\Delta_{\mathrm{tar}}}{c},
$$

where $\Delta_{\text {ref }}$ and $c$ are the distance between event and the surrounding reference station and assumed phase speeds shown in Table 1, respectively. A positive value of $\tau_{\text {syn }}$ means a delay of the reference station seismogram against the target station.

Next, for the matched seismograms of each component, we calculated three parameters. One is the searched maximum cross-correlation coefficient, $C$,

$$
C=\frac{\sum_{i=1}^{N} u_{\mathrm{tar}}\left(t_{i}\right) u_{\mathrm{ref}}\left(t_{i}+\tau\right)}{\sqrt{\left(\sum_{i=1}^{N} u_{\mathrm{tar}}^{2}\left(t_{i}\right)\right)\left(\sum_{i=1}^{N} u_{\mathrm{ref}}^{2}\left(t_{i}+\tau\right)\right)}},
$$

where $u_{\mathrm{tar}}\left(t_{i}\right), u_{\mathrm{ref}}\left(t_{i}\right), N$, and $\tau$ are seismograms at target and reference stations, the number of discrete time points, and the lag time which gives the maximum cross-correlation coefficient, respectively. The second parameter is the ratio of the amplitude at the target station to that at the reference station, $R$ :

$$
R=\frac{\sum_{i=1}^{N} u_{\mathrm{tar}}\left(t_{i}\right) u_{\mathrm{ref}}\left(t_{i}+\tau\right)}{\sum_{i=1}^{N} u_{\mathrm{ref}}^{2}\left(t_{i}+\tau\right)}
$$

Table 1 Group and phase velocities assumed in this study

\begin{tabular}{llll}
\hline & Period & $\begin{array}{l}\text { Rayleigh wave } \\
(\mathbf{k m} / \mathbf{s})\end{array}$ & $\begin{array}{l}\text { Love wave } \\
(\mathbf{k m} / \mathbf{s})\end{array}$ \\
\hline Group velocity & ALL & 3.9 & 4.4 \\
Phase velocity & 50 to $100 \mathrm{~s}$ & 4.0 & 4.4 \\
& 100 to $200 \mathrm{~s}$ & 4.2 & 4.5 \\
\hline
\end{tabular}


Values of $R$ smaller than 1.0 mean that the amplitudes at the target station are smaller than those at the surrounding reference station, and values larger than 1.0 so that the amplitudes at the target station are larger than those at reference station. The third parameter is a lag time error, $\tau_{\text {error }}=\tau-\tau_{\text {syn }}$. The deviations of the lag time, $\tau$, which give the cross-correlation coefficients larger than $0.98 \times C$ typically range within \pm 2 and \pm 4 s for the periods of 50 to $100 \mathrm{~s}$ and 100 to $200 \mathrm{~s}$, respectively. $R$ and $\tau_{\text {error }}$ are indexes to evaluate the seismometer's amplitude and phase responses, respectively.

An example of the comparison between seismograms at a target station (TYS) and a reference station (IYG) is shown in Figure 2. As can be seen in the figure, the surface-wave parts of the seismograms at the two stations are well correlated, and $C$ is approximately 1.0. In addition, their amplitudes are comparable with the $R$ values of around 1.0, and the lag time error, $\tau_{\text {erron }}$ is close to 0.0. Therefore, we can infer that the ground motions within a period range of 50 to $200 \mathrm{~s}$ were observed correctly at these two stations and that the instrumentation responses were normal.

\section{Spatial range of reference stations}

As the distance between the target and the reference stations increased, the correlation between two observed waveforms decreased. This was considered likely to be due to the heterogeneity of velocity structures and the fact that waveforms at distant reference stations are unavailable for evaluating target instrumentation conditions. We defined the spatial range of the surrounding reference stations for a target station from the following exploratory analysis. For surface waves of events with $M_{W}$ of 7.0 or larger, which have a significantly high

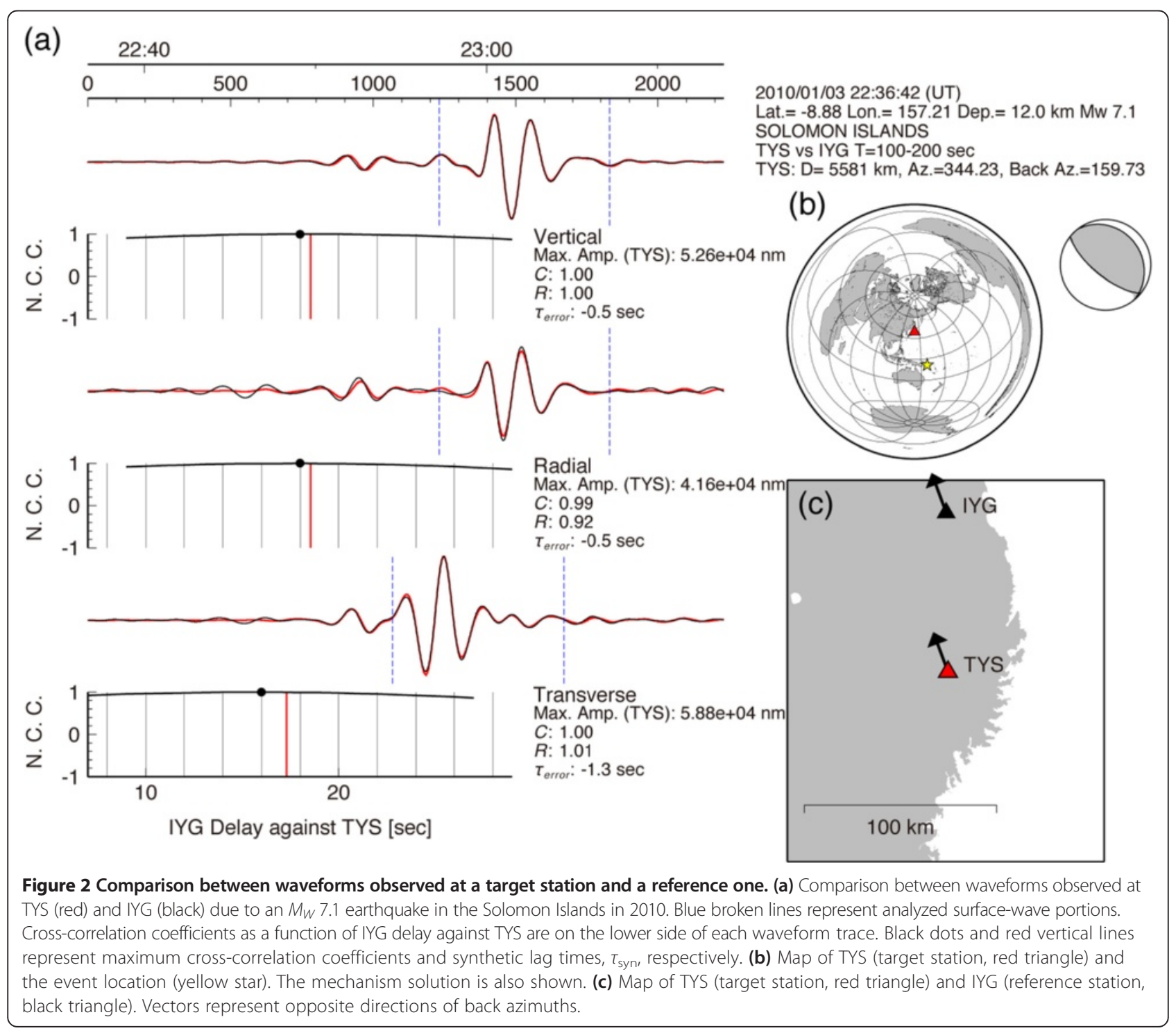


signal-to-noise ratio, we calculated $C$ values for three reference stations closest to a target station at each event time. Figure 3 shows the estimated $C$ values as a function of the distance between the target and reference stations. Since we included analyses for teleseismic events in the early stage of the network construction, when the number of F-net stations was small and the station density was low, the $C$ values for station distances larger than $100 \mathrm{~km}$ were calculated with significant frequencies. The upper 90th percentage of $C$ values were found to be larger than 0.7 up to the distance of $200 \mathrm{~km}$, except for distances within $50 \mathrm{~km}$ for horizontal components at periods of 100 to $200 \mathrm{~s}$. Therefore, stations at distances of $200 \mathrm{~km}$ or less from a target station were selected as reference stations. Note that the high background noise levels at currently inactive stations in region A (Figure 1a), where the station density was higher than other regions, cause the low $C$ values at fairly close distances for the horizontal components at periods of 100 to $200 \mathrm{~s}$, as shown in Figure 3.

\section{Comparison with observed seismograms at multiple stations} Figure 4 shows a comparison of records at TYS with the reference stations at distances of $200 \mathrm{~km}$ or less from TYS. As can be seen in the figure, all of the reference records, except for the vertical component record at TMR, agree well with those at TYS. The $C$ value of the vertical component against TMR is as high as those against the other stations. However, the amplitude at TMR is systematically smaller by approximately $30 \%$

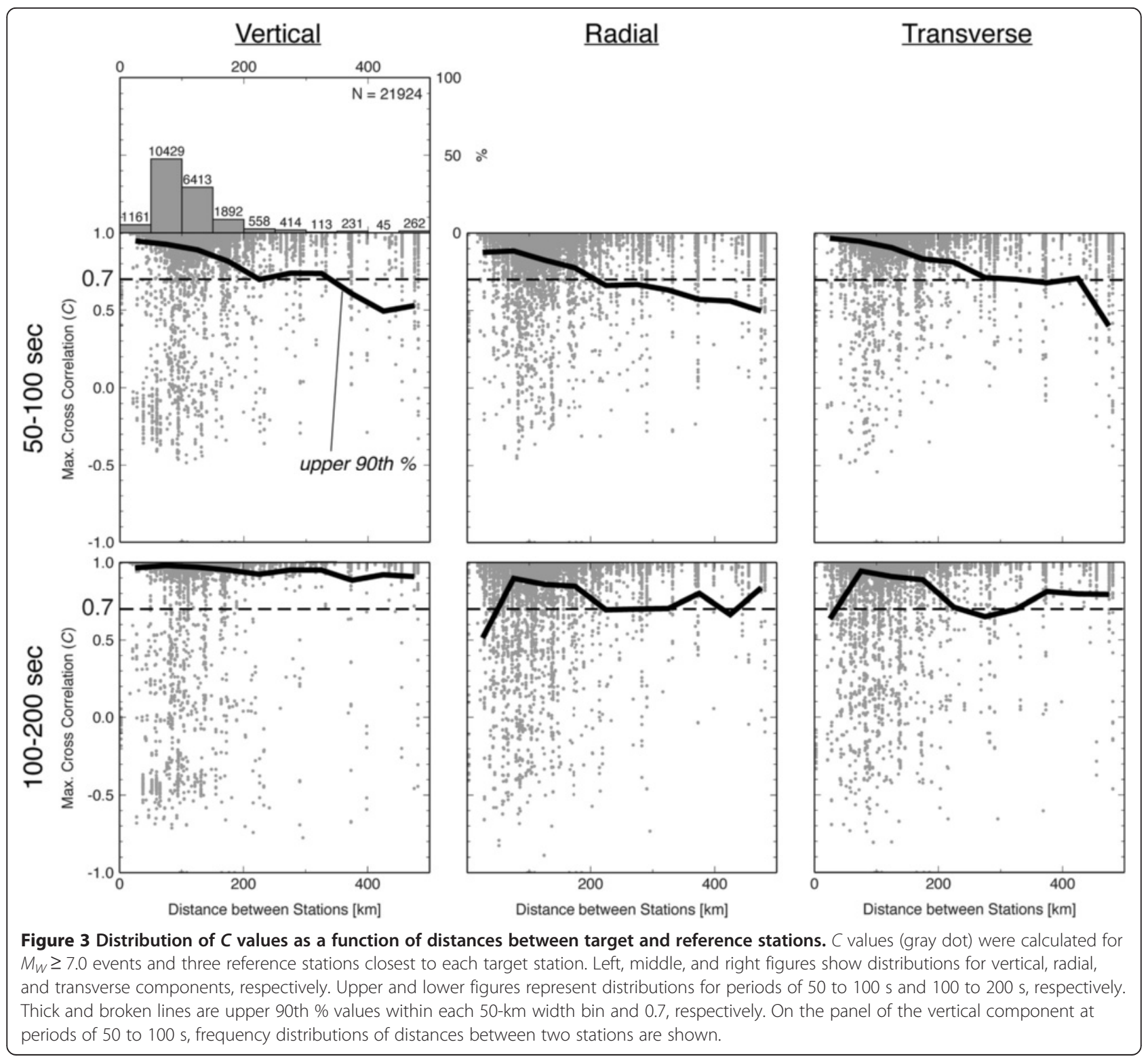




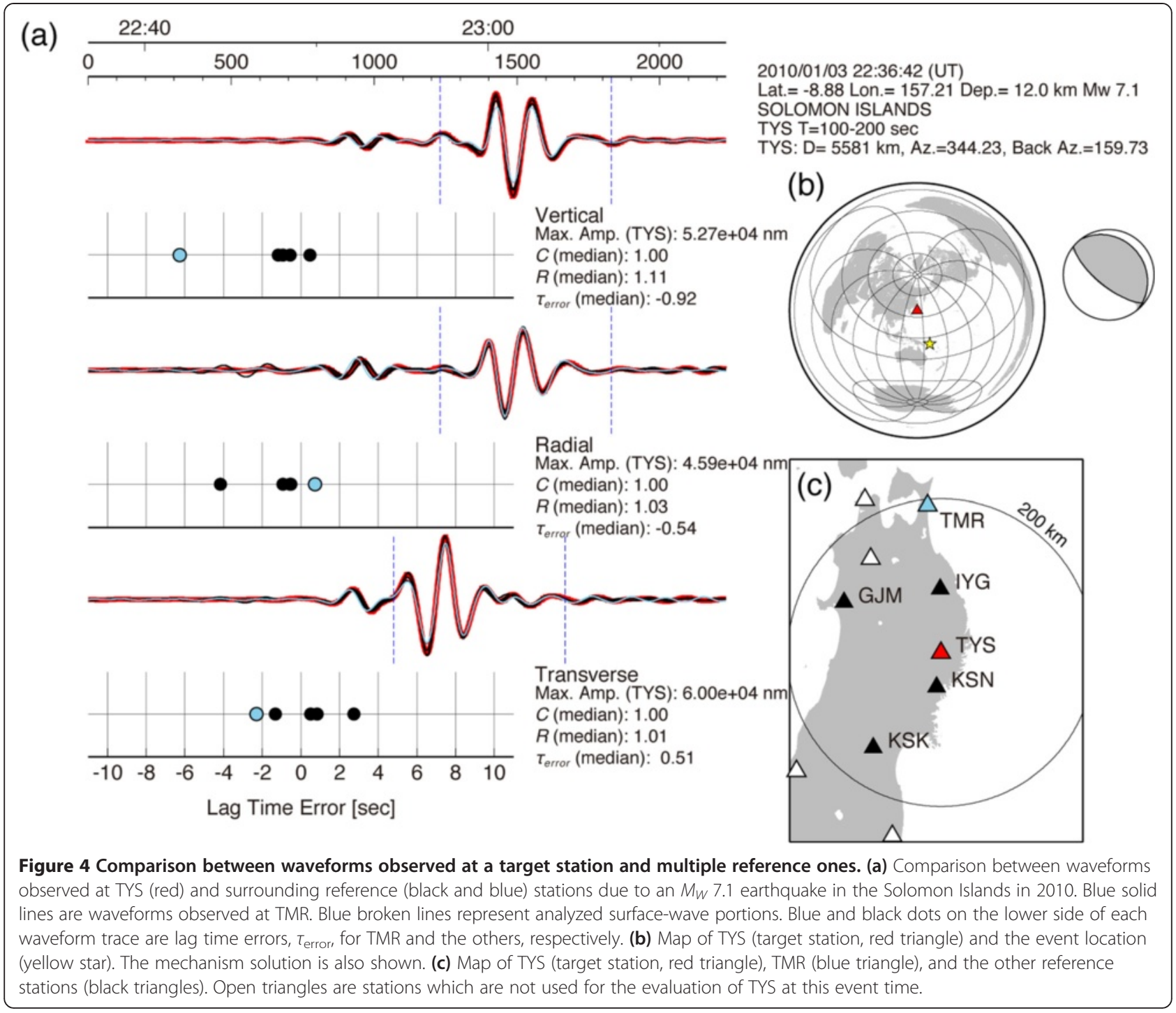

than that at TYS, and an absolute value of the lag time error, $\tau_{\text {error }}$ for TMR is significantly larger than those for the other stations. When TYS was compared solely with TMR, we were unable to determine which records at the two stations are anomalous. However, by making a comparison with multiple reference station records, we could deduce that the ground motion at TYS was observed correctly and that the TMR instrumentations appeared to be malfunctioning. As a result, we could assess the instrumentation health at the target station, TYS, robustly without distortion from instrumentation problems at a small subset of surrounding stations, such as TMR. In the following section, we will discuss how instrumentation health is evaluated at a target station based on the medians of index parameters for a teleseismic event using at least three surrounding reference stations. Note that the seismometers at stations on isolated islands and at the edge of F-net were not evaluated (Figure 1a) because the number of surrounding reference stations was insufficient.

\section{Evaluation of instrument responses on horizontal components}

Although the vertical component output from the instrument can be evaluated directly using three index parameters, the parameters on horizontal components do not necessarily correspond to evaluations about the original outputs on the NS and EW components because we rotated the sensor outputs to produce radial and transverse components. Using the following analysis, we estimated the index parameters for NS and EW components. First, we converted each index parameter on a two-dimensional $x-y$ plane as follows: 


$$
\begin{aligned}
C: \quad(x, y) & =(C \cos \theta, C \sin \theta) \\
R: \quad(x, y) & =((\log R-\log 0.2) \cos \theta,(\log R-\log 0.2) \sin \theta), \\
\tau_{\text {error }}: & (x, y)=\left(\left(\tau_{\text {error }}+11.0\right) \cos \theta,\left(\tau_{\text {error }}+11.0\right) \sin \theta\right)
\end{aligned}
$$

where $\theta$ is the azimuth of the positive direction of radial/transverse components for each event-station pair measured clockwise from north (Figure 5). Then, we approximated the converted data of two components for $M$ teleseismic events, $\left(x_{j}, y_{j}\right), j=1,2, \ldots, 2 M$, as an ellipse, $x^{2} / a^{2}+y^{2} / b^{2}-1=0$, for each index parameter so as to minimize the residual sum of squares, $Q=\sum_{j=1}^{2 M}\left(x_{j}^{2} / a^{2}+y_{j}^{2} / b^{2}-1\right)^{2} \cdot a$ and $b$ represent points at the intersection of estimated ellipse with $x$ - and $y$ axes corresponding NS- and EW-axes, respectively, and we define index parameters for NS and EW components as follows:

$$
\begin{array}{lll}
C: & a(\mathrm{NS}) & b(\mathrm{EW}) \\
R: & 10.0^{a} \times 0.2(\mathrm{NS}) & 10.0^{b} \times 0.2(\mathrm{EW}) \\
\tau_{\text {error }}: & a-11.0(\mathrm{NS}) & b-11.0(\mathrm{EW})
\end{array}
$$

For $R$ and $\tau_{\text {error }}$ we did not use data with $C$ smaller than 0.8 . In order to assess the significance of the estimated ellipse, the variance reduction against the circle expected when instrument responses of both horizontal components are normal is calculated as $\left(1.0-Q / Q_{0}\right) \times$ $100 \%$, where:

$$
\begin{aligned}
C: Q_{0} & =\sum_{j=1}^{2 M}\left(\frac{x_{j}^{2}}{1.0^{2}}+\frac{x_{j}^{2}}{1.0^{2}}-1\right)^{2} \\
R: Q_{0} & =\sum_{j=1}^{2 M}\left(\frac{x_{j}^{2}}{(\log 1.0-\log 0.2)^{2}}+\frac{x_{j}^{2}}{(\log 1.0-\log 0.2)^{2}}-1\right)^{2} \\
\tau_{\text {error }}: Q_{0} & =\sum_{j=1}^{2 M}\left(\frac{x_{j}^{2}}{(0.0+11.0)^{2}}+\frac{x_{j}^{2}}{(0.0+11.0)^{2}}-1\right)^{2}
\end{aligned}
$$

Standard deviations of estimated index parameters for NS and EW components are evaluated by the Bootstrap method (Efron 1979) with 200 samples. Figure 5 shows the results of index-parameter estimation at a period range of 100 to $200 \mathrm{~s}$ for TYS station using ten teleseismic events occurring from 20 September 2009 to 10 January 2010. For all the index parameters, the converted data is distributed along the expected normal circle. This indicates that the estimated parameters for both NS and EW components are close to the standard values and variance reductions are relatively low. Consequently, we could conclude that the instrument responses of both horizontal components had no apparent abnormalities at that time.

\section{Frequency of instrumentation response assessments}

In our proposed method, the temporal resolution used to evaluate instrumentation conditions at a target station depends fully on the occurrence of teleseismic events. Figure 6 shows frequency distributions of the number of

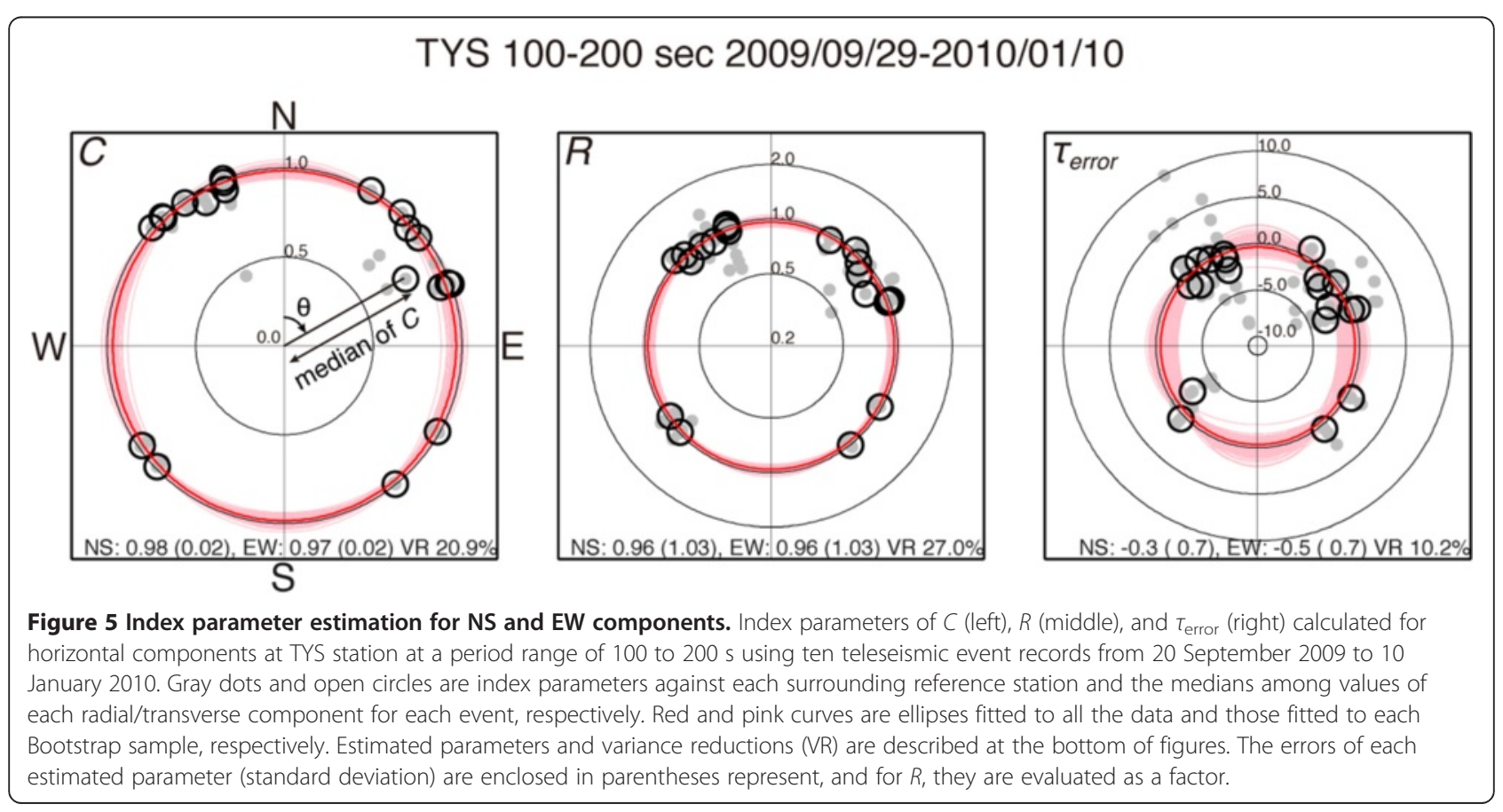




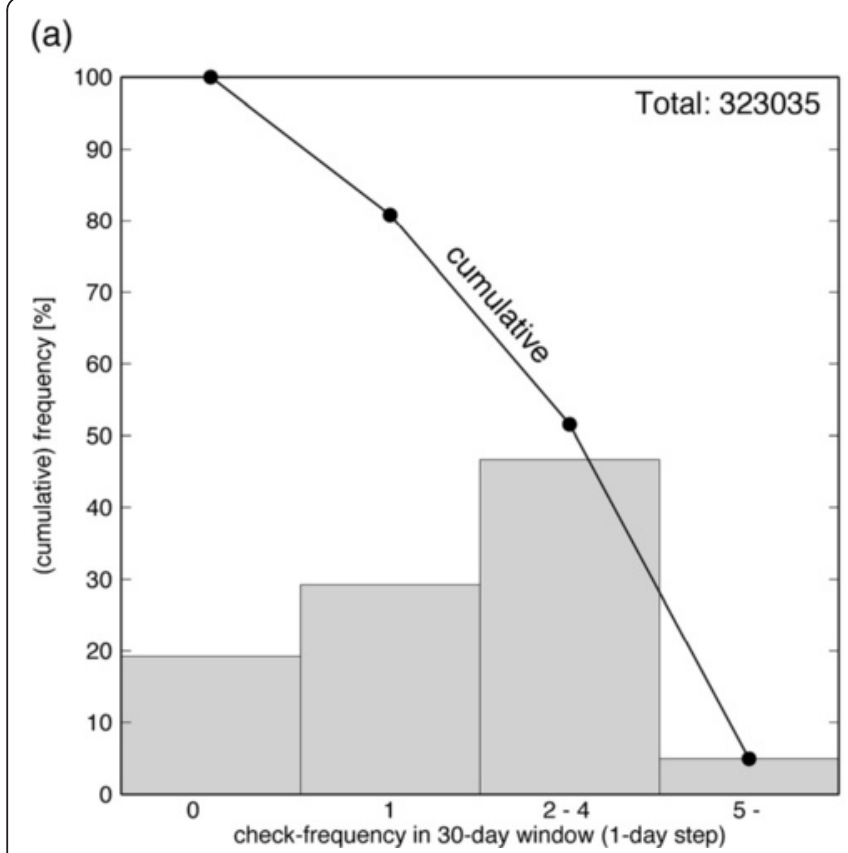

(b)

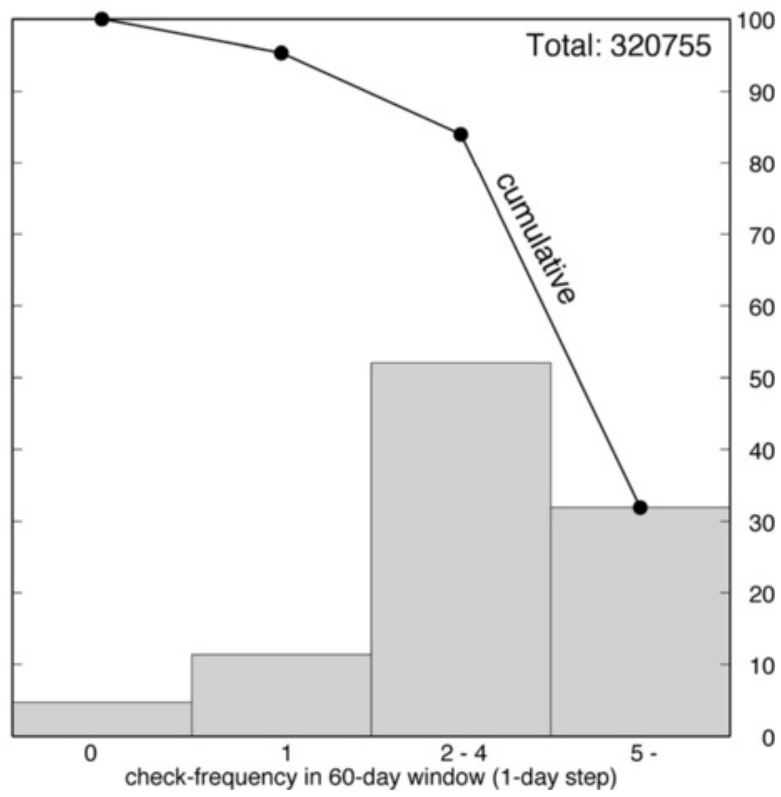

Figure 6 Frequency distribution of the number of analyzed teleseismic events within moving time windows. Frequency distribution of the number of analyzed teleseismic events for the 100 to $200 \mathrm{~s}$ vertical component at all the target stations within (a) a 30-day and (b) a 60-day time window with the 1-day step (gray bars). Solid lines represent cumulative frequencies in order from the larger number.

teleseismic events analyzed for 100 to $200 \mathrm{~s}$ vertical components at all target stations within 30- and 60-day time windows in 1-day increments. We count the number of events for which the record at each target station is compared with at least three reference stations within each time window. For the 30-day time windows, the frequencies of the time windows within which no teleseismic events used to evaluate instrument response had occurred are about 20\%. For the 60-day windows, the same figure is about $5 \%$. Therefore, the proposed method allows us to perform analysis at least once each 30 days for approximately $80 \%$ of the observing period and once each 60 days for $95 \%$.

\section{Overall trend of index parameters}

Figure 7 presents the temporal changes in the index parameters, $C, R$, and $\tau_{\text {error }}$ for the vertical component at TYS. As can be seen in the figure, the index parameter medians do not show any systematic fluctuations from standard values of 1.0, 1.0, and 0.0, respectively. Thus, we can presume that the instrumentation response of the vertical component at TYS has been normal at 50 to $200 \mathrm{~s}$ periods.

Figure 8 shows the temporal changes in the index parameters for the NS and EW components at TYS, which were estimated by fitting of ellipses to data for continuous ten teleseismic events with five-event step. In the same manner as the vertical component, the index parameters of both components appear around each standard value and have no significant temporal changes. Therefore, no errors were recognized in the instrument responses of either horizontal component.

Most of the evaluated index parameters range around standard values as well as those at TYS. Figure 9 indicates frequency distributions of the index parameter medians of vertical, radial, and transverse components. The $94 \%$ and $89 \%$ of the median $C$ values are larger than 0.8 for the 50 to $100 \mathrm{~s}$ and 100 to $200 \mathrm{~s}$ periods, respectively. In cases with $C$ values larger than 0.8 , more than $90 \%$ of the quartile deviation values of $R$ and $\tau_{\text {error }}$ are smaller than a factor of 1.2 and $4 \mathrm{~s}$, respectively, and changes larger than these values would be possibly detected based on our proposed method. The scatters in the index parameters could be mainly caused not by instrument problems but by unmodeled effects such as lateral and/or small-scale heterogeneity in Earth. The $82 \%$ and $86 \%$ levels of the $R$ values were found to be distributed within a factor of 1.2 for the 50 to 100 and 100 to $200 \mathrm{~s}$ periods, respectively. In the same way, the $94 \%$ and $92 \%$ of $\tau_{\text {error }}$ are within $\pm 4 \mathrm{~s}$. Consequently, it can be concluded that significant instrument errors at the period range of 50 to $200 \mathrm{~s}$ have not appeared in most F-net broadband seismograms.

\section{Examples of abnormal instrumentation responses}

Although most of the index parameters were within acceptable values, anomalies covering a period of several years were discovered at a few F-net stations. The 


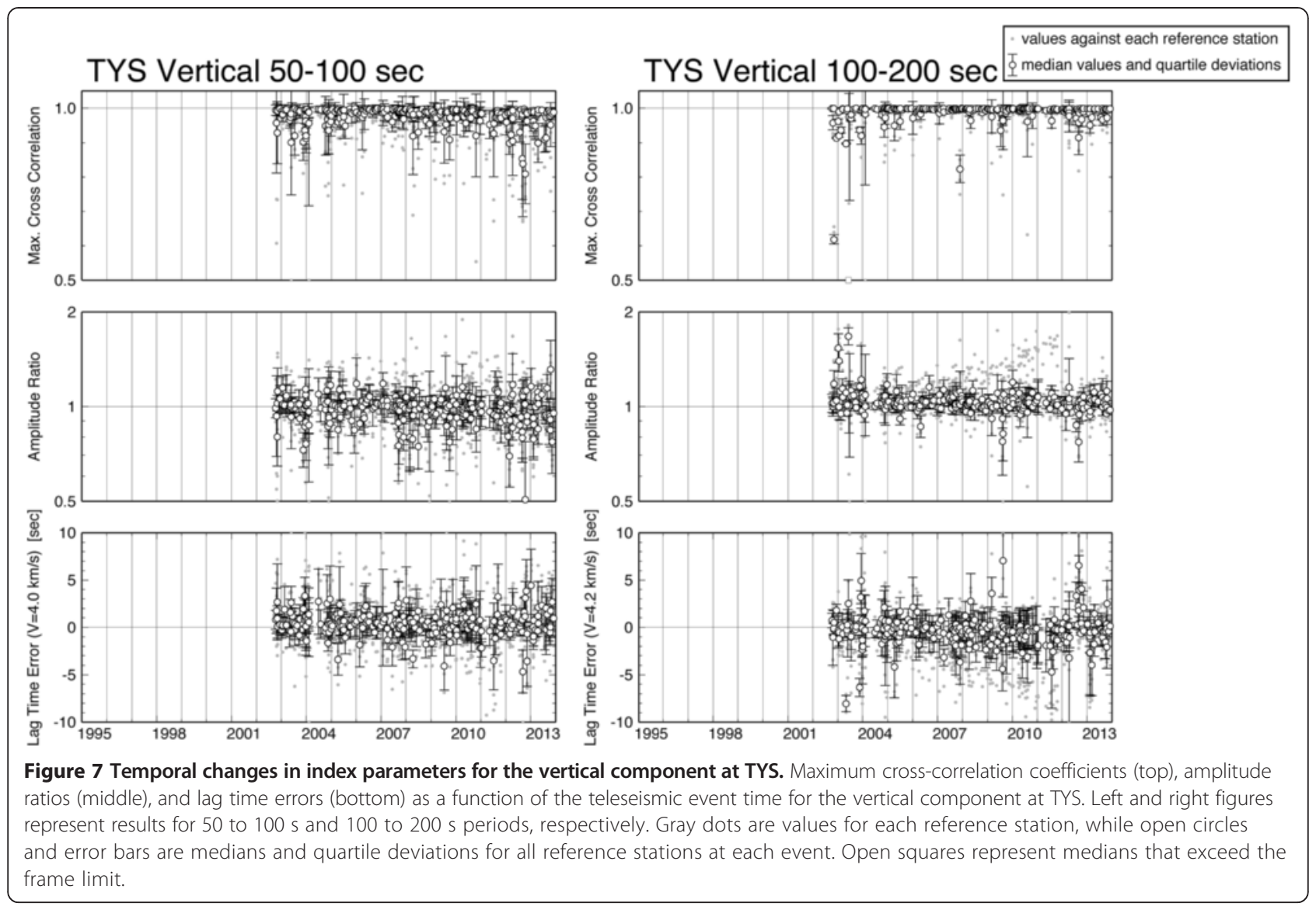

temporal changes in the index parameters for the vertical component at SHR are shown in Figure 10. Here, it can be seen that the $C$ and $\tau_{\text {error }}$ values have been distributed around 1.0 and 0.0 , respectively, since observations began around the end of 2002. However, the amplitude ratios, $R$, were approximately 0.5 until 2012 for both the 50 to 100 and 100 to 200 s periods but settled at around 1.0 after the host-box of the STS-2 seismometer was replaced in September 2012. This indicates that a host-box malfunction caused the gain error.

Figure 11 shows the temporal variations in index parameters for the vertical component at TMR. Here, the $C$ value was found to be close to 1.0 since 2000 , while

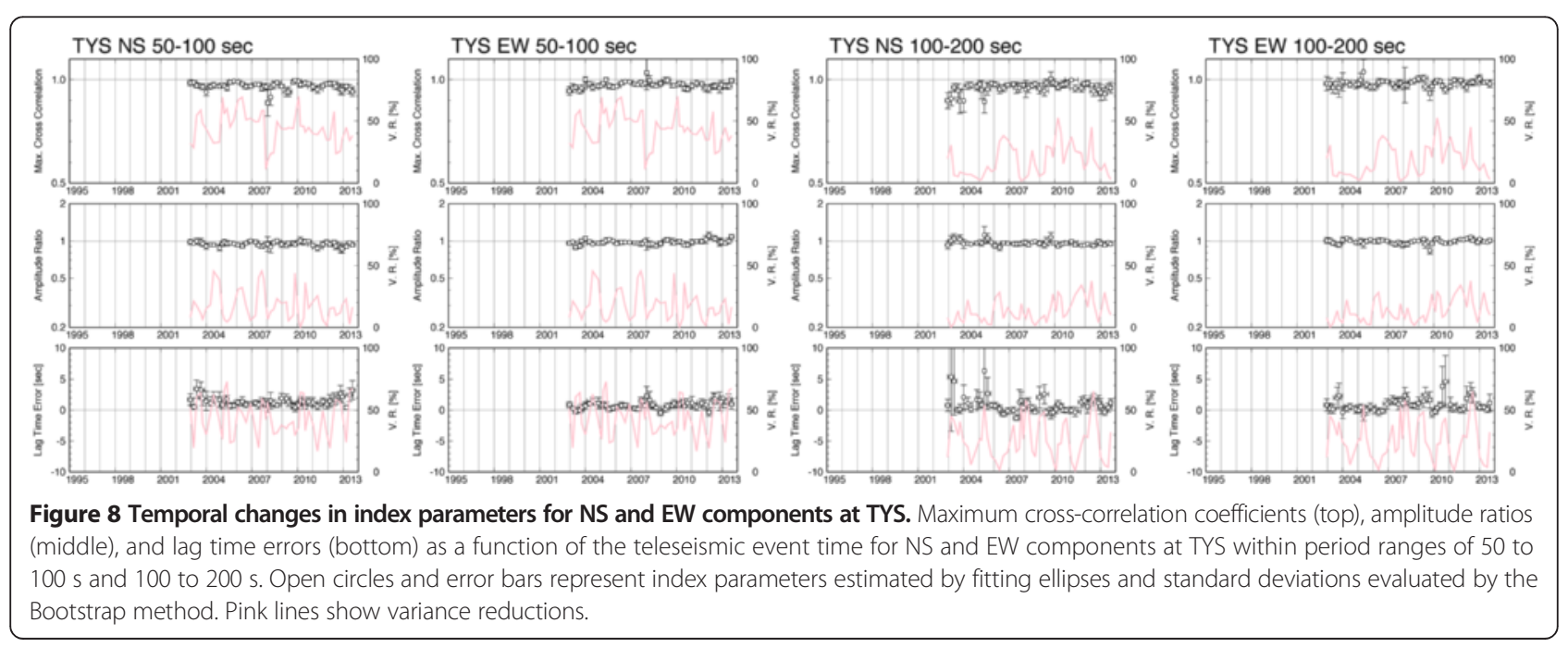




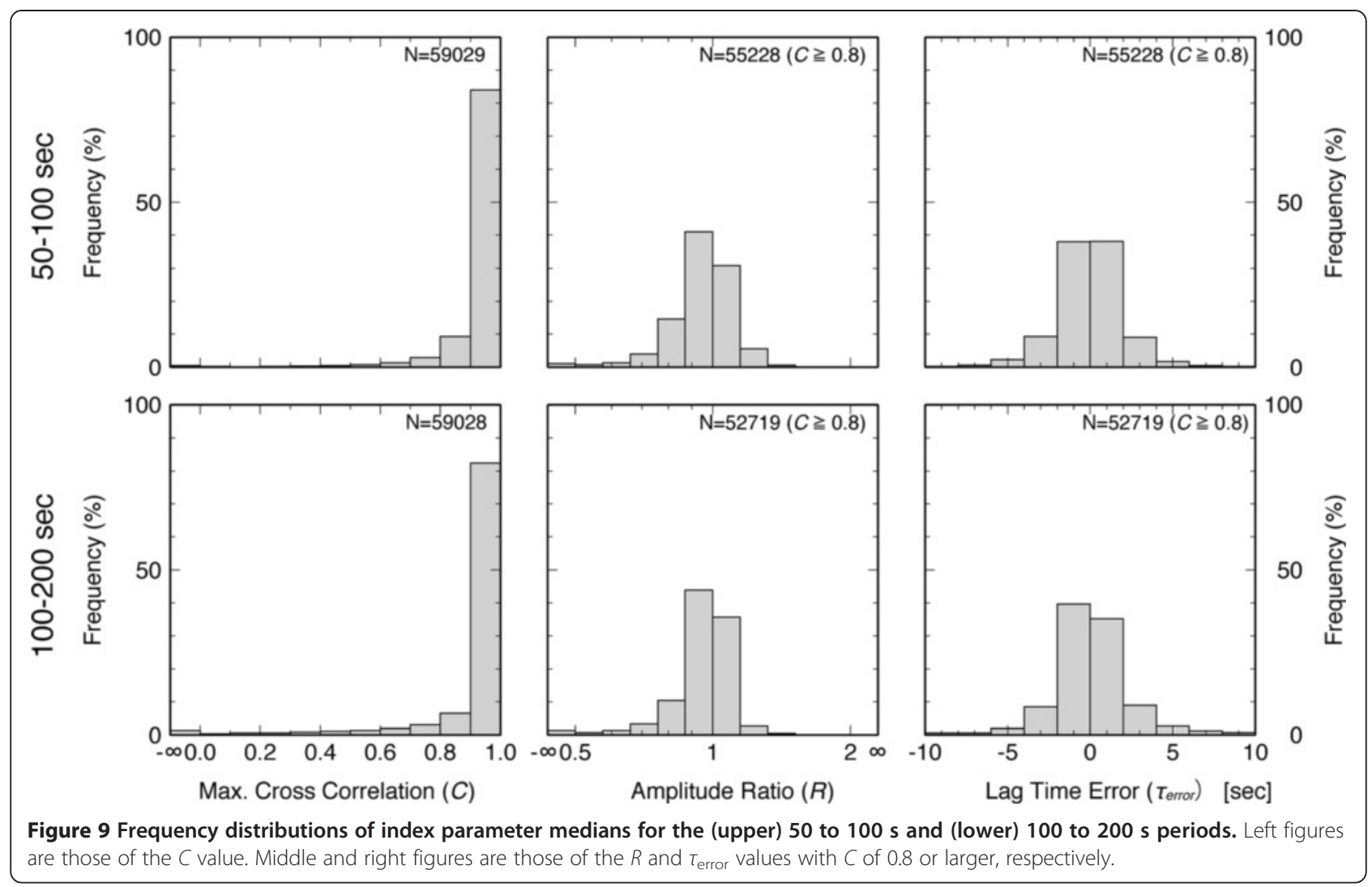

the $R$ value at 100 to $200 \mathrm{~s}$ period had declined gradually from 2001 before returning to 1.0 in the end of 2011. The $\tau_{\text {error }}$ value had increased gradually until 2011 and then turned to 0.0. At periods of 50 to $100 \mathrm{~s}$, significant changes in $R$ and $\tau_{\text {error }}$ appeared from 2009 to 2011. In November 2011, we leveled the vertical STS-1 sensor for the first time since it was installed, after which the $R$ and $\tau_{\text {error }}$ values became approximately 1.0 and 0.0 , respectively. It is believed that a continuous increase of sensor tilt until 2011 could have induced amplitude and phase frequency response errors.

In Figure 12, we show a case of vertical component at station TKD where gradual decreases of $R$ and abrupt increases of $\tau_{\text {error }}$ occurred in 2003, after which $R$ and $\tau_{\text {error }}$ had moved steadily toward 0.2 and 0.0 , respectively. From 2003 to $2008, C$ values for the 100 to $200 \mathrm{~s}$ periods sometimes showed low values, and those values for both the 50 to 100 and 100 to 200 s periods declined even more significantly in 2008. In February and May 2008, during maintenance of the STS-1 seismometer at TKD, insulation failures in the cables between the sensor and FBE were discovered. In August 2008, TKD was updated from an STS-1 to an STS-2 seismometer, and the index parameters had shown normal values since that time.
Also at TKD, NS component records prior to 2008 showed seismometer response errors. Figure 13 represents temporal changes in the index parameters for NS and EW components at that station. From 2000 to 2008, $R$ values as low as 0.5 were estimated for the NS component at both period ranges of 50 to $100 \mathrm{~s}$ and 100 to $200 \mathrm{~s}$. At the same time, $\tau_{\text {error }}$ were 5.0 or larger. The variance reductions for these estimations were relatively high as $70 \%$ to $90 \%$. Therefore, we can infer that the NS component seismometer responses were not consistent with those published between 2000 and 2008. During maintenance conducted in 2008, cable insulation failures between sensor and FBE were reported for the NS component STS- 1 seismometer. $R$ and $\tau_{\text {error }}$ values became normal after the STS-1 was replaced with a STS-2 seismometer in 2008.

\section{Differences in anomalies between STS-1 and STS-2 seismometers}

Simultaneous $R$ and $\tau_{\text {error }}$ anomalies, similar to those recorded at TMR (Figure 11) and TKD (Figures 12 and 13), also appear at other stations where STS-1 seismometers have been installed. Figure 14a shows the relationship between the $R$ and $\tau_{\text {error }}$ medians for the vertical component, which can be evaluated directly by the surface wave comparisons. We plot the relationships for STS-1 

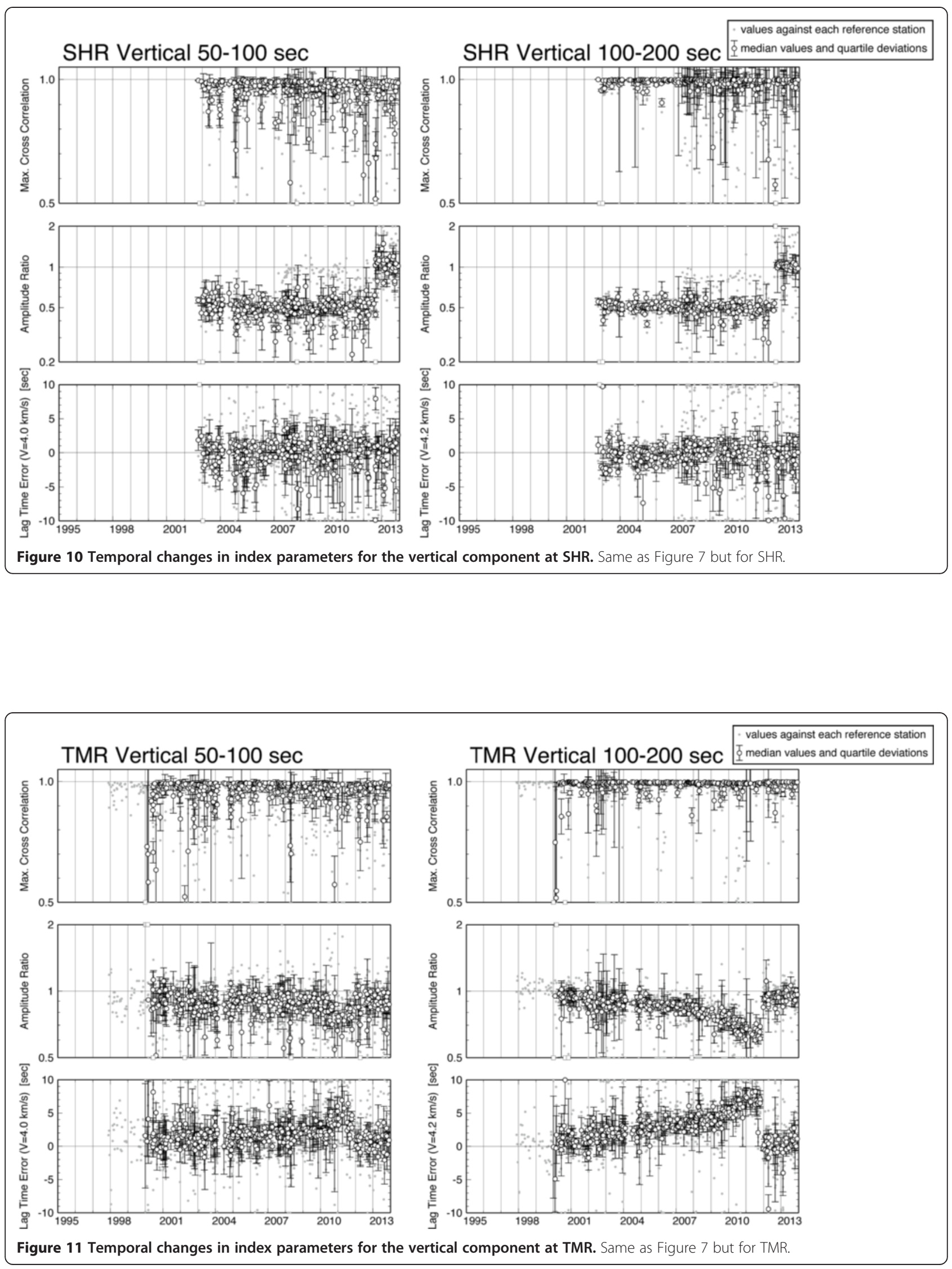


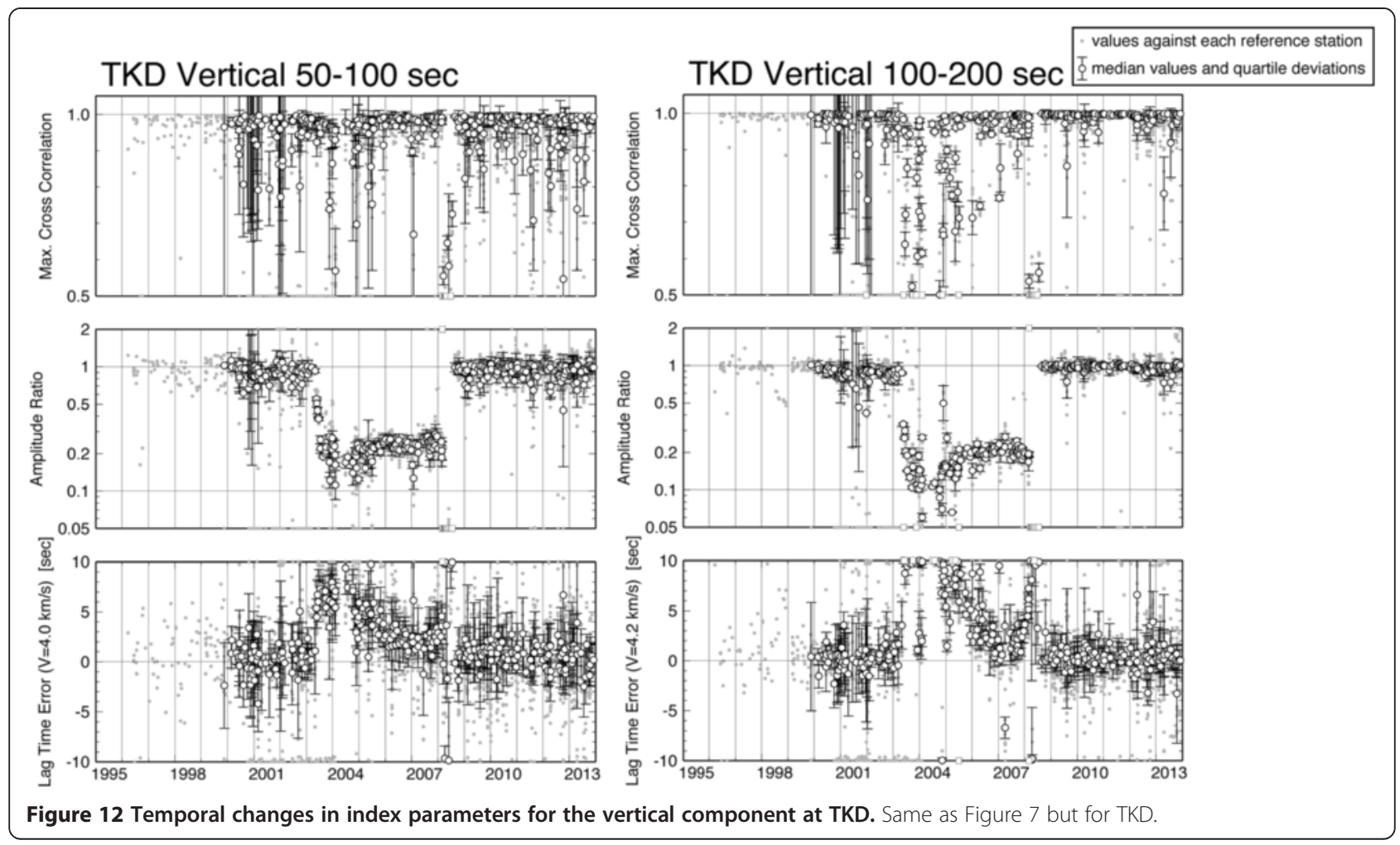

and STS-2 seismometers separately. As can be seen in the figure, a decrease in $R$ and an increase in $\tau_{\text {error }}$ are typical abnormal conditions of STS-1 seismometers. The relationship between $R$ and $\tau_{\text {error }}$ expected when the damping factor at the 360-s corner of the amplitude frequency response of STS-1, $h$, changes (Figure 14b) is also shown in Figure 14a, and we can see that the observed index parameter anomaly trend is consistent with the increase of $h$. In addition, changes in $R$ for 50 to $100 \mathrm{~s}$ periods smaller than those for 100 to $200 \mathrm{~s}$ can also be represented as a result of the $h$ deviation, because that deviation is more influential on the

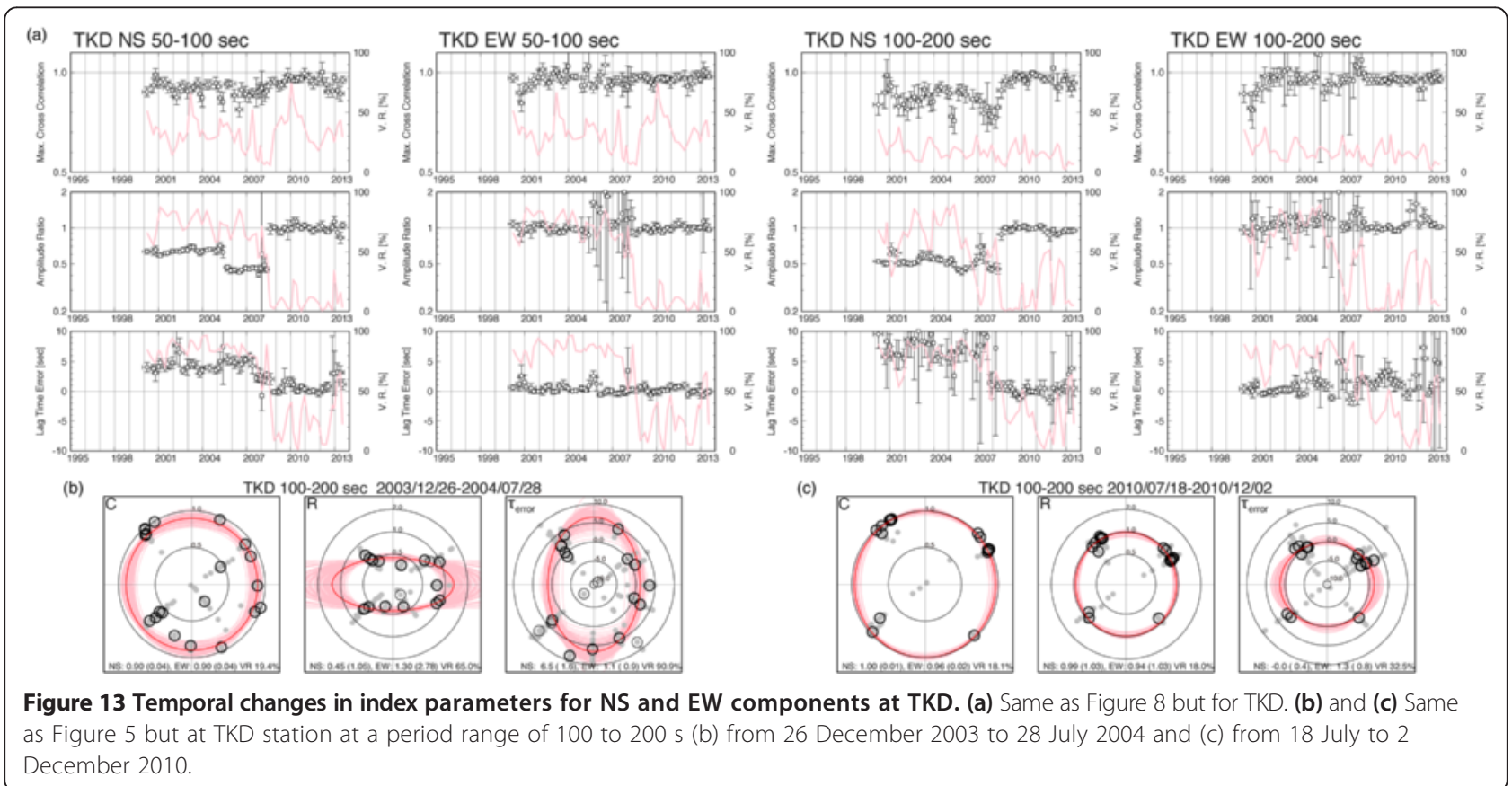




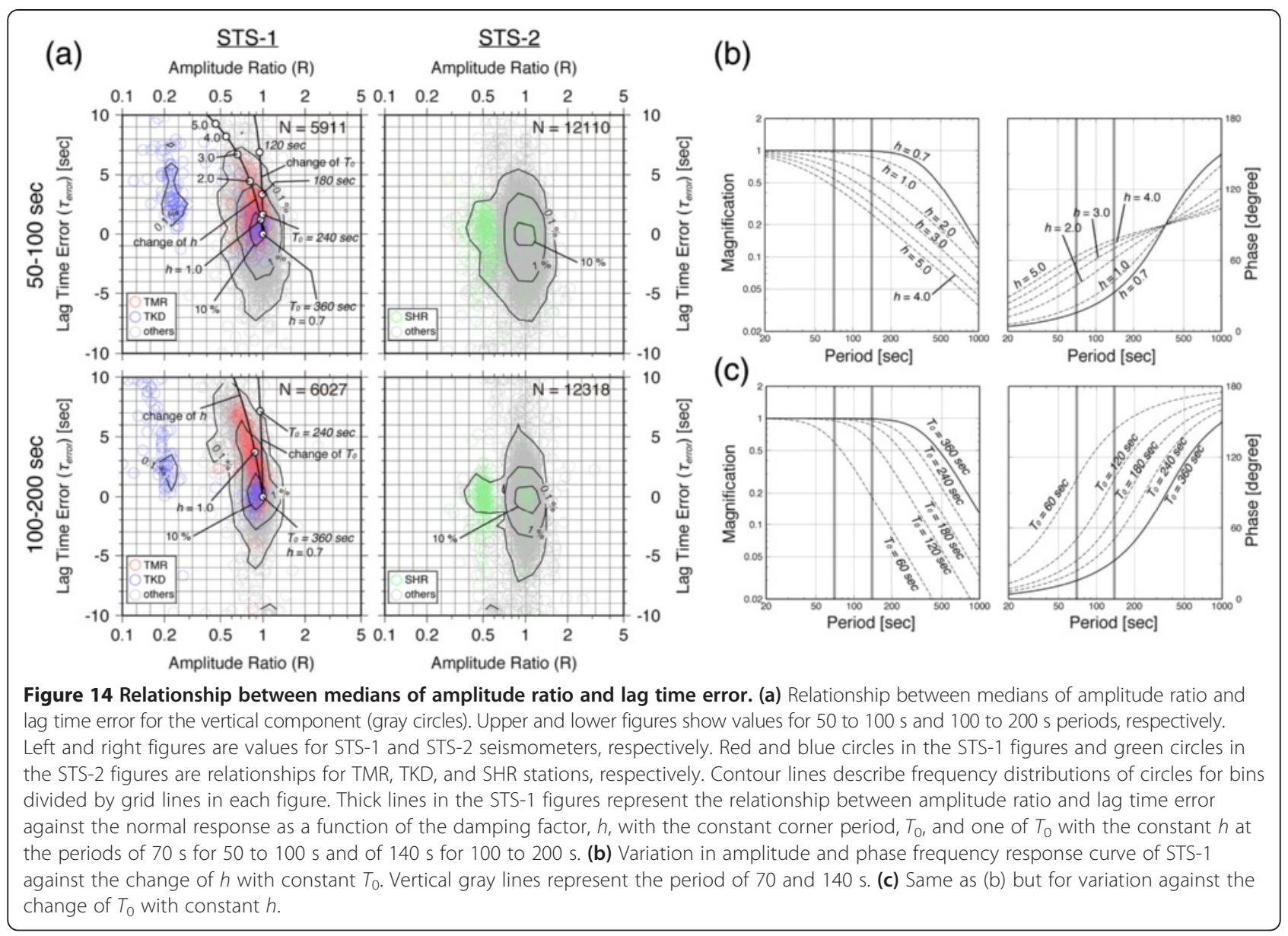

instrumentation responses at periods closer to the 360-s corner. On the other hand, the change of the corner period, $T_{0}$, with constant $h$ (Figure 14c) cannot explain the observed anomaly trend.

Previous studies have reported problems related to STS-1 seismometer overdamping (Yamada 2001; Yuki and Ishihara 2002; Hutt and Ringler 2011). These studies attributed such errors to sensor tilting, improperly insulated connectors and cables between the FBE and sensor, and humid air inside FBE. Some F-net STS-1 sensors had not been leveled for periods longer than 5 years and are typically installed in the back of vaults exposed to humid air. All these factors contributed to STS-1 seismometer overdamping at F-net stations.

In the case of STS-2 seismometers, no common systematic anomaly could be found among the multiple sensors examined (Figure 14a). Furthermore, index parameters at 100 to $200 \mathrm{~s}$ periods for STS-2 seismometers were more concentrated in the standard values than those for STS-1 seismometers, and F-net STS-2 seismometers were found to work more stably without typical response errors.

\section{Conclusions}

We develop a method to assess broadband seismometer health based on comparisons between teleseismic surface wave records at target stations and those at multiple surrounding stations. The calculation of three index parameters, $C, R$, and $\tau_{\text {error }}$ enables us to evaluate $i n$ situ instrumentation conditions including amplitude and phase responses at 50 to $200 \mathrm{~s}$ periods in observation networks whose station intervals were smaller than $200 \mathrm{~km}$. We applied this method to NIED F-net seismometers and found that most index parameters could be calculated at least once every 60 days, except for stations in isolated islands and network edges. Approximately $75 \%$ of the total calculated index parameters were found to register around the standard values, and most seismometers have operated in accordance with reported responses. However, at a few stations, instrumentation response problems such as gain errors and simultaneous amplitude and phase frequency response errors were found to be ongoing for several years. Indeed, overdamping errors appeared to have been especially common at the 360-s corner of several F-net STS-1 seismometers. 
Our method enables operators to check instrumentation responses in regional broadband seismometer networks with station intervals smaller than $200 \mathrm{~km}$. The systematic monitoring of seismometer health is essential to operating observation networks and, consequently, to providing high-quality seismic data. In addition, by referring to the results of systematic monitoring, researchers can avoid using data that has been contaminated by instrumentation errors and thus prevent misleading analyses.

Our proposed method has limitations related to station density, the frequency of teleseismic events used to check the instrument responses, and the detection capability of index parameter changes. First, since our method requires station intervals smaller than $200 \mathrm{~km}$, instrumentation health at stations on isolated islands and network edges cannot be assessed (Figure 1a). Other analyses using only single station data, such as monitoring of background noise (Ringler et al. 2010) and ZH ratio of Rayleigh wave, which requires precise information about the instrument response to estimate the velocity structure beneath the station (e.g., Tanimoto and Rivera 2008), will be effective for these stations. In the case of NIED F-net, a low-gain broadband seismometer is also installed at each station. These sensors could be used to improve the seismometer density and thus allow instrumentation health evaluations at isolated stations. Second, the limitation on the check frequency is fully dependent on the occurrence of the teleseismic events. In order to assess instrumentation health at higher frequency and detect sudden changes of instrument responses, it might be beneficial to combine our method with other routinely applicable approaches, such as daily background noise level monitoring (Ringler et al. 2010). Finally, the detection capability of changes in amplitude ratio and lag time error was approximately a factor of 1.2 and $4 \mathrm{~s}$. More detailed analyses of surface waves, especially in the frequency domain, could improve this capability. The improvement could also be done by considering the multi-path effects of Rayleigh waves (e.g., Forsyth and Li 2005) and the extraction of Rayleigh wave component based on polarization analysis (e.g., Vidale 1986).

\section{Availability and requirements}

Project name: Research on earthquakes and volcanoes based on a fundamental precise monitoring network

Project home page: http://www.fnet.bosai.go.jp/top.php? LANG=en

Operating system: Mac OSX

Programming language: Ruby

Other requirements: SAC (Seismic Analysis Code), GMT

License: SAC

Any restrictions to use by non-academics: no nonacademic use

\section{Abbreviations}

CMT: centroid moment tensor; FBE: feedback electronics; GMT: Generic Mapping Tools; GSN: Global Seismographic Network; NIED: National Research Institute for Earth Science and Disaster Prevention; SAC: Seismic Analysis Code.

\section{Competing interests}

The authors declare that they have no competing interests.

\section{Authors' contributions}

TK developed the data analysis tool, analyzed the data, and drafted the manuscript. HM collected instrumentation maintenance histories at each F-net station and suggested revisions to the manuscript. TM contributed to discussions on the scientific contents and suggested revisions to the manuscript. All authors read and approved the final manuscript.

\section{Acknowledgements}

We would like to express our appreciation for the very constructive comments of the two anonymous reviewers that helped us in revising and improving the manuscript. GMT software (Wessel and Smith 1998) was used to create the figures.

\section{Author details}

${ }^{1}$ National Research Institute for Earth Science and Disaster Prevention, 3-1, Tennodai, Tsukuba, Ibaraki 305-0006, Japan. ${ }^{2}$ Association for the Development of Earthquake Prediction, 3-1, Tennodai, Tsukuba, Ibaraki 305-0006, Japan

Received: 6 February 2015 Accepted: 9 April 2015

Published online: 23 April 2015

\section{References}

Davis P, Berger J (2007) Calibration of the global seismographic network using tides. Seismol Res Lett 78(4):454-459

Davis P, Ishii M, Masters G (2005) An assessment of the accuracy of GSN sensor response information. Seismol Res Lett 76(6):678-683

Dziewonski AM, Chou T-A, Woodhouse JH (1981) Determination of earthquake source parameters from waveform data for studies of global and regional seismicity. J Geophys Res 86:2825-2852, doi:10.1029/JB086iB04p02825

Efron B (1979) Bootstrap methods: another look at the jackknife. Ann Stat 7:1-126, doi:10.1214/aos/1176344552

Ekström G, Dalton CA, Nettles M (2006) Observations of time-dependent errors in longperiod instrument gain at global seismic stations. Seismol Res Lett 77(1):12-22

Ekström G, Nettles M, Dziewonski AM (2012) The global CMT project 2004-2010: centroid-moment tensors for 13,017 earthquakes. Phys Earth Planet Inter 200-201:1-9, doi:10.1016/j.pepi.2012.04.002

Forsyth DW, Li A (2005) Seismic array analysis of two-dimensional variations in surface wave phase velocity and azimuthal anisotropy in the presence of multipathing interference. In: Seismic earth: array analysis of broadband seismograms geophysical monograph series (Vol. 157, pp. 81-97). doi:10.1029/GM157

Fukuyama E, Ishida M, Hori S, Sekiguchi S, Watada S (1996) Broadband seismic observation conducted under the FREE SIA project. Rep Nat'I Res Inst Earth Sci Disas Prev 57:23-31 (in Japanese with English abstract)

Fukuyama E, Ishida M, Dreger DS, Kawai H (1998) Automated seismic moment tensor determination by using on-line broadband seismic waveforms. Zisin 51:149-156 (in Japanese with English abstract)

Hutt CR, Ringler AT (2011) Some possible causes of and corrections for STS-1 response changes in the global seismographic network. Seismol Res Lett 82(4):560-571

Ito Y, Obara K, Shiomi K, Sekine S, Hirose H (2007) Slow earthquakes coincident with episodic tremors and slow slip events. Science 310:503-506

Matsumoto T, Hori S, Matsubayashi H (2009) Broadband seismic observation-NIED F-net. Zisin 61:S9-S18 (in Japanese with English abstract)

Matsumura M, Ito Y, Kimura H, Obara K, Sekiguchi S, Hori S, Kasahara K (2006) Development of accurate and quick analysis system for source parameters (AQUA). Zisin 59:167-184 (in Japanese with English abstract)

Okada Y, Kasahara K, Hori S, Obara K, Sekiguchi S, Fujiwara H, Yamamoto A (2004) Recent progress of seismic observation networks in Japan - Hi-net, F-net, K-NET and KiK-net. Earth Planets Space 56:xv-xxviii

Ringler AT, Gee LS, Hutt CR, McNamara DE (2010) Temporal variations in global seismic station ambient noise power levels. Seismol Res Lett 81(4):605-613 
Ringler AT, Gee LS, Marshall B, Hutt CR, Storm T (2012) Data quality of seismic records from the Tohoku, Japan, earthquake as recorded across the Albuquerque seismological laboratory networks. Seismol Res Lett 83(3):575-584 Tanimoto T, Rivera $L$ (2008) The ZH ratio method for long-period seismic data: sensitivity kernels and observational techniques. Geophys J Int 172(1):187-198, doi:10.1111/j.1365-246X.2007.03609.x

Vidale JE (1986) Complex polarization analysis of particle motion. Bssa 76(5):1393-1405 Wessel P, Smith WHF (1998) New, improved version of the Generic Mapping Tools released, EOS Trans. AGU 79:579, doi:10.1029/90EO00426

Yamada I (2001) A problem in long-term stability of STS-1 seismometer. Zisin 53:259-262 (in Japanese)

Yoshizawa K, Miyake K, Yomogida K (2010) 3-D upper mantle structure beneath Japan and its surrounding region from inter-station dispersion measurements of surface waves. Phys Earth Planet Inter 183:4-19

Yuki Y, Ishihara Y (2002) Methods for maintaining the performance of STS-1 seismometer. Front Res Earth Evolution 2:1-5

\section{Submit your manuscript to a SpringerOpen ${ }^{\circ}$} journal and benefit from:

- Convenient online submission

- Rigorous peer review

- Immediate publication on acceptance

- Open access: articles freely available online

- High visibility within the field

- Retaining the copyright to your article

Submit your next manuscript at $>$ springeropen.com 